\title{
In vitro studies on oxidative stress-independent, Ag nanoparticles-induced cell toxicity of Candida albicans, an opportunistic pathogen
}

This article was published in the following Dove Press journal:

International Journal of Nanomedicine

\section{Venkatraman Srinivasan \\ Radhakrishnan' \\ Surya Prakash Dwivedi \\ Mohammed Haris Siddiqui ${ }^{3}$ \\ Tulika Prasad' \\ 'Advanced Instrumentation Research Facility (AIRF), Jawaharlal Nehru University, New Delhi, ${ }^{2}$ School of Biotechnology, IFTM University, Moradabad, ${ }^{3}$ Department of Bioengineering, Integral University, Lucknow, Uttar Pradesh, India}

Correspondence: Tulika Prasad Advanced Instrumentation Research Facility (AIRF), Jawaharlal Nehru University, New Delhi I 10067, India Email prasadtulika@hotmail.com

\begin{abstract}
Silver nanoparticles (AgNps) have attracted maximal attention among all metal nanoparticles, and the study of their biological properties has gained impetus for further medical adoption. This study evaluated the cellular and molecular mechanisms associated with the action of AgNps against an opportunistic pathogen, Candida albicans. Spherical, stable AgNp (average size $21.6 \mathrm{~nm}$ ) prepared by a chemical reduction method showed minimum inhibitory concentration (required to inhibit the growth of $90 \%$ of organisms) at $40 \mu \mathrm{g} / \mathrm{mL}$. AgNps have been reported to induce oxidative stress-mediated programmed cell death through the accumulation of intracellular reactive oxygen species (ROS). However, this study demonstrated that intracellular levels of AgNp-induced ROS could be reversed by using antioxidant ascorbic acid, but the sensitivity of AgNp-treated Candida cells could not be completely reversed. Moreover, in addition to the generation of ROS, the AgNps were found to affect other cellular targets resulting in altered membrane fluidity, membrane microenvironment, ergosterol content, cellular morphology, and ultrastructure. Thus, the generation of ROS does not seem to be the sole major cause of AgNp-mediated cell toxicity in Candida. Rather, the multitargeted action of $\mathrm{AgNps}$, generation of ROS, alterations in ergosterol content, and membrane fluidity together seem to have potentiated anti-Candida action. Thus, this "nano-based drug therapy" is likely to favor broad-spectrum activity, multiple cellular targets, and minimum host toxicity. AgNps, therefore, appear to have the potential to address the challenges in multidrug resistance and fungal therapeutics.
\end{abstract}

Keywords: antifungal, nanomedicine, ROS, drug resistance

\section{Introduction}

Bacterial drug resistance has been the primary cause of concern, but a rise in antifungal resistance has now begun to pose a challenge to therapeutics. ${ }^{1}$ Life-threatening systemic and superficial mycoses caused by opportunistic fungal pathogens account for $\sim 40 \%$ mortality. ${ }^{1,2}$ Among these, dimorphic and otherwise commensal Candida spp. form part of human microbial flora and are fourth most common cause of nosocomial infections, especially among immunocompromised individuals. ${ }^{1,2}$ High toxicity, low host tolerance, narrow spectrum of antifungal drugs, and increasing incidence of azole resistance further complicate the treatment of invasive Candida albicans infections. ${ }^{2}$

With global emergence of antimicrobial resistance as an increasing threat to public health arises the need to develop new and safe agents with broad-spectrum activity and minimal host side effects. ${ }^{1}$ The potential of metal nanoparticles in medicine has been exploited for early detection, diagnosis, and disease treatment, but their biological properties still remain unexplored. Among all nanoparticles, silver nanoparticles submit your manuscript Dovepress f 
(AgNps) have attracted maximum attention. ${ }^{3}$ Silver is known for its use as disinfectants and antimicrobials and has been reported to exhibit higher microbial toxicity than other heavy metals. ${ }^{3}$ For safer medical use of AgNps, more clinical trials and research at the level of molecular biology are needed to delineate intracellular pathways involved and evaluate potential host toxicity. This study is an effort to elucidate the cellular and molecular mechanisms associated with AgNp activity against opportunistic fungal pathogen, C. albicans.

\section{Materials and methods}

Analytical grade chemicals and high-performance liquid chromatography grade solvents were obtained from HIMedia (Mumbai, Maharashtra, India) and Fisher Scientific (Mumbai, Maharashtra, India). Fluconazole, dichlorofluorescein diacetate (DCFDA), ascorbic acid (AA), lyticase, 1, 6-diphenyl-1, 3, 5-hexatriene (DPH), and tetrahydrofuran were procured from Sigma Aldrich (St Louis, MO, USA).

\section{Chemical synthesis and characterization of $\mathrm{AgNp}$}

AgNp was synthesized by the chemical reduction of silver nitrate by sodium borohydrate and characterized using zeta potential, transmission electron microscope (TEM), scanning electron microscope (SEM) equipped with energy dispersive spectroscopy (EDS), ultraviolet spectrophotometer, and X-ray diffraction (XRD) powder. ${ }^{4}$

\section{Evaluation of antifungal activity}

The antifungal activity of AgNps was assessed using minimum inhibitory concentration (MIC) and spot assays as described elsewhere. ${ }^{5,6} \mathrm{MIC}$ was determined by the broth microdilution method in accordance with the recommendations of the Clinical and Laboratory Standard Institute. ${ }^{6,7}$ Briefly, cells were grown for 14-16 hours on agar plates (exponentially growing log phase cells) and resuspended in $0.9 \%$ saline to give an optical density of 0.1 at $600 \mathrm{~nm}\left(\mathrm{OD}_{600}\right)$, which corresponded to cell number $0.5-1 \times 10^{6}$ cells $/ \mathrm{mL}$. Furthermore, the cells were diluted 100-fold in the yeast extract peptone dextrose (YEPD) medium to make the final concentration of cells $0.5-1 \times 10^{4}$ cells $/ \mathrm{mL}$. The cells were allowed to grow at different concentrations of $\mathrm{AgNps}$ at $30^{\circ} \mathrm{C}$ with continuous shaking. Readings were recorded at $600 \mathrm{~nm}$ at every 4-hour interval and compared with growth control (no AgNps). For the spot assay, the cells were taken from the overnight grown YEPD agar plate and resuspended in $0.9 \%$ saline. The OD at $600 \mathrm{~nm}$ of cell suspension was adjusted to 0.1 and serially diluted five times. Then, $5 \mu \mathrm{L}$ of each serial dilution of yeast culture was spotted onto the YEPD plates in the presence of various concentrations of AgNps only and both AgNps and antioxidant AA ( $5 \mathrm{mM} / \mathrm{mL})$. Two growth controls were maintained separately - one without AgNps and antioxidant and the second without AgNps but with antioxidant. Growth differences were recorded after incubation of the plates at $30^{\circ} \mathrm{C}$ for 48 hours. ${ }^{8}$

\section{Assessing intracellular reactive oxygen species (ROS) in the $\mathrm{AgNp}$-treated cells and reversal of endogenous ROS to basal levels using antioxidant AA}

Endogenous ROS levels of $C$. albicans were detected by an oxidant-sensitive fluorescent dye DCFDA as previously reported with slight modifications. ${ }^{5}$ The cells were grown till mid-exponential phase in the presence of only AgNps (5 and $40 \mu \mathrm{g} / \mathrm{mL}$ ), both AgNps and antioxidant AA (5 mM), and in the absence of both (growth control). The cells were then harvested, followed by washing with phosphatebuffered saline (PBS) buffer, $\mathrm{pH} 7.4$, twice to remove the media. About $10^{7}$ cells were resuspended in $3 \mathrm{~mL}$ of PBS, $\mathrm{pH}$ 8.4. The fluorescent probe DCFDA (final concentration $10 \mu \mathrm{M}$ ) was added to each cell suspension and incubated at $30^{\circ} \mathrm{C}$ for 1 hour. Fluorescence intensity was measured in a Perkin Elmer L55 spectrofluorimeter at respective excitation and emission wavelengths of 488 and $540 \mathrm{~nm}$ with slit widths of 5 and $10 \mathrm{~nm}$, respectively. The blank (absence of fluorescent probe) was maintained separately to avoid autofluorescence.

\section{Assessing membrane fluidity, cellular microenvironment, and sterol content in $\mathrm{AgNp}$-treated cells}

Intracellular ROS levels were estimated as described before. ${ }^{5}$ The changes in membrane fluidity and cellular microenvironment were analyzed by steady state and time-resolved fluorescence polarization studies using a fluorescent probe, DPH. ${ }^{5,6}$ Membrane ergosterol extracted by heptane was quantitated as described earlier., ${ }^{5,6}$

\section{Electron microscopy for the study of surface morphology and cellular ultrastructure of the treated cells}

Alterations in the surface morphology and cellular ultrastructure of AgNp-treated cells were determined by using SEM and TEM. ${ }^{9}$ 
A

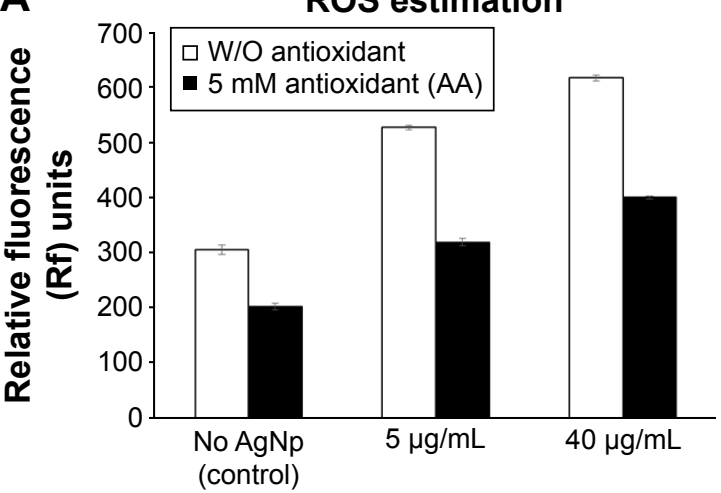

$\operatorname{AgNp}(\mu \mathrm{g})$
B Spot assay

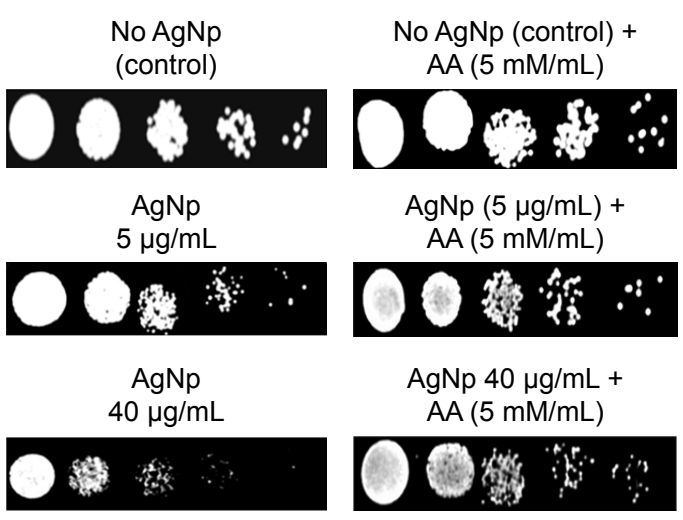

Figure I Effect of antioxidant on AgNp augmented ROS and anti-Candida activity of AgNp.

Notes: (A) Intracellular ROS levels \pm standard deviation of the mean of three sets of experiments in control (untreated) and AgNp-treated cells both in the absence (open bars) and the presence of antioxidant AA (shaded bars); (B) anti-Candida activity of AgNps as determined by spot assay in absence and the presence of antioxidant $\mathrm{AA}$.

Abbreviations: $\mathrm{AA}$, ascorbic acid; $\mathrm{AgNp}$, silver nanoparticle; $\mathrm{ROS}$, reactive oxygen species; W/O, without.

\section{Results and discussion}

TEM revealed the formation of well-dispersed AgNp of an average size of $21.6 \mathrm{~nm}$ (Figure S1). The zeta potential value of $-34.2 \mathrm{mV}$ indicated the stability of AgNps. SEM micrographs showed well-dispersed AgNps with spherical and smooth surface morphology (Figure S2). The presence of strong peak was observed in EDS at $3 \mathrm{keV}$, typical for $\mathrm{Ag}$ (Figure S3) and did not reveal the presence of any major element other than Ag. ${ }^{10}$ A single peak showing a maximum absorbance at $398.87 \mathrm{~nm}$ was obtained for AgNps confirming their stability and uniformity (Figure S4). The XRD spectrum obtained for AgNps at $2 \theta$ values ranging between $30^{\circ}$ and $80^{\circ}$ was in agreement with XRD spectra of pure crystalline silver structures published by the Joint Committee on Powder Diffraction Standards (JCPDS file no 04-0783). This confirmed the presence of nanocrystals of $\mathrm{Ag}$ in our experiments, as evident from the four intense diffraction peaks at $2 \theta$ values of $38.1^{\circ}$, $44.5^{\circ}, 64.5^{\circ}$, and $77.5^{\circ}$ corresponding to (111), (200), (220), and (311) planes, respectively, for silver (Figure S5). ${ }^{11}$

MIC (required to inhibit the growth of $90 \%$ of organisms $\left[\mathrm{MIC}_{90}\right]$ ) of AgNps for the C. albicans cells was $40 \mu \mathrm{g} / \mathrm{mL}^{-1}$. Anti-C. albicans effects of AgNps were confirmed by spot assays.

In accordance with previous reports, we found $\mathrm{AgNp}$ dose-dependent increase in intracellular ROS levels in treated C. albicans cells (Figure 1A). ${ }^{12}$ Interestingly, even reversing cellular ROS levels using AA could not completely reverse the AgNp susceptibilities of treated cells (Figure 1B). In addition to endogenous ROS generation, $\mathrm{AgNp}$ treatment also resulted in altered cellular ergosterol content, membrane fluidity, cellular microenvironment, ultrastructure, and surface morphology (unpublished data). Therefore, the generation of intracellular ROS does not appear to be the only major cause of AgNp-mediated C. albicans cell toxicity. Further experimental investigations are underway to elucidate the underlying mechanisms.

\section{Conclusion}

The antifungal potential of AgNps appears to be in coherence with broad-spectrum activity, multiple cellular targets, and minimum host toxicity. Thus, this "nano-based drug therapy" has the potential to provide a promising approach to combat multidrug resistance for better therapeutic management.

\section{Acknowledgments}

The work presented in this paper has been supported by grants to TP from DBT (BT/PR5110/MED/29/497/2012 and BT/BI/12/045/2008), CSIR (OSDD/HCP001/11FYP/201011/134), JNU-UPEII Scheme, and DST-PURSE, India, and infrastructural support from JNU. VSR thanks DBT, India, for Senior Research Fellowship.

\section{Disclosure}

The authors report no conflicts of interest in this work.

\section{References}

1. Kanafani ZA, Perfect JR. Resistance to antifungal agents: mechanisms impacts. Clin Infect Dis. 2008;46(1):120-128.

2. Prasad T, Sethumadhavan S, Fatima Z. Altered ergosterol biosynthetic pathway - an alternate multidrug resistance mechanism independent of drug efflux pump in human pathogenic fungi C. albicans. In: Méndez Vilas A, editor. Science Against Microbial Pathogens: Communicating Current Research and Technological Advances. Microbiology Series. Badajoz, Spain: Formatex Research Center; 2011:757-768. 
3. Ge L, Li Q, Wang M, Ouyang J, Li X, Xing MM. Nanosilver particles in medical applications: synthesis, performance toxicity. Int $J$ Nanomedicine. 2014;9:2399-2407.

4. Pal S, Tak YK, Son JM. Does the antibacterial activity of silver nanoparticles depend on the shape of the nanoparticle? A study of the gram-negative bacterium Escherichia coli. Appl Environ Microbiol. 2007;73(6): 1712-1720.

5. Prasad T, Hameed S, Manoharlal R, et al. Morphogenic regulator EFG1 affects the drug susceptibilities of pathogenic Candida albicans. FEMS Yeast Res. 2010;10(5):587-596.

6. Prasad T, Chandra A, Mukhopadhyay CK, Prasad R. Unexpected link between-iron drug resistance of Candida spp.: iron depletion enhances membrane fluidity drug diffusion, leading to drug-susceptible cells. Antimicrob Agents Chemother. 2006;50(11):3597-3606.

7. Wayne, PA. Reference Method for Broth Dilution Antifungal Susceptibility Testing of Yeasts. Approved Standard M27-A3. 3rd ed. Wayne, PA, USA. Clinical and Laboratory Standards Institute (CLSI); 2008.
8. Mukhopadhyay K, Prasad T, Saini P, Pucadyil TJ, Chattopadhyay A, Prasad R. Membrane sphingolipid ergosterol interactions are important determinants of multi drug resistance in Candida albicans. Antimicrob Agents Chemother. 2004;48(5):1778-1787.

9. Walker LA, Munro CA, de Bruijn I, Lenardon MD, McKinnon A, Gow NA. Stimulation of chitin synthesis rescues Candida albicans from echinocandins. PLoS Pathog. 2008;4(4):1-12.

10. Singh R, Wagh P, Wadhwani S, et al. Synthesis, optimization, and characterization of silver nanoparticles from Acinetobacter calcoaceticus and their enhanced antibacterial activity when combined with antibiotics. Int J Nanomedicine. 2013;8:4277-4290.

11. Kalimuthu K, Suresh Babu R, Venkataraman D, Bilal M, Gurunathan S. Biosynthesis of silver nanocrystals by Bacillus licheniformis. Colloids Surf B Biointerfaces. 2008;65(1):150-153.

12. Hwang IS, Lee J, Hwang JH, Kim KJ, Lee DG. Silver nanoparticles induce apoptotic cell death in Candida albicans through the increase of hydroxyl radicals. FEBS J. 2012;279(7):1327-1338. 


\section{Supplementary materials}

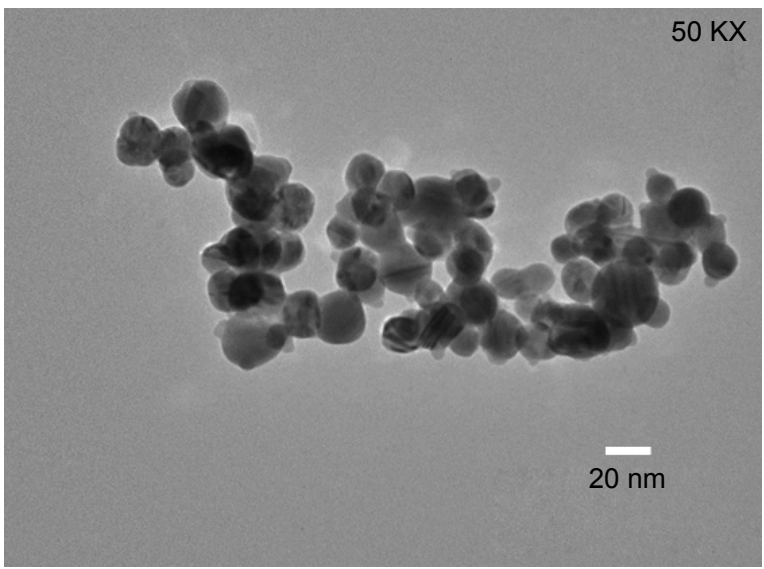

Figure SI TEM micrograph of chemically synthesized AgNps.

Abbreviations: AgNps, silver nanoparticles; TEM, transmission electron microscope.

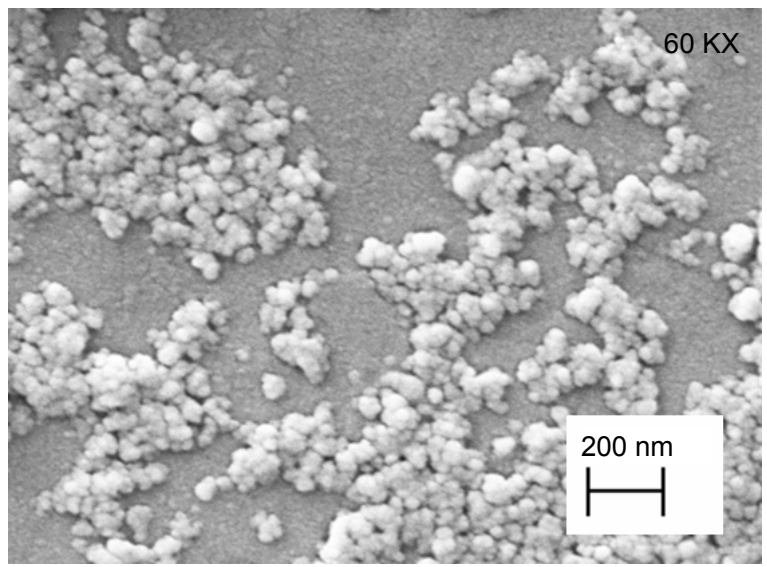

Figure S2 SEM micrograph of $\mathrm{AgNps}$.

Abbreviations: AgNps, silver nanoparticles; SEM, scanning electron microscope.

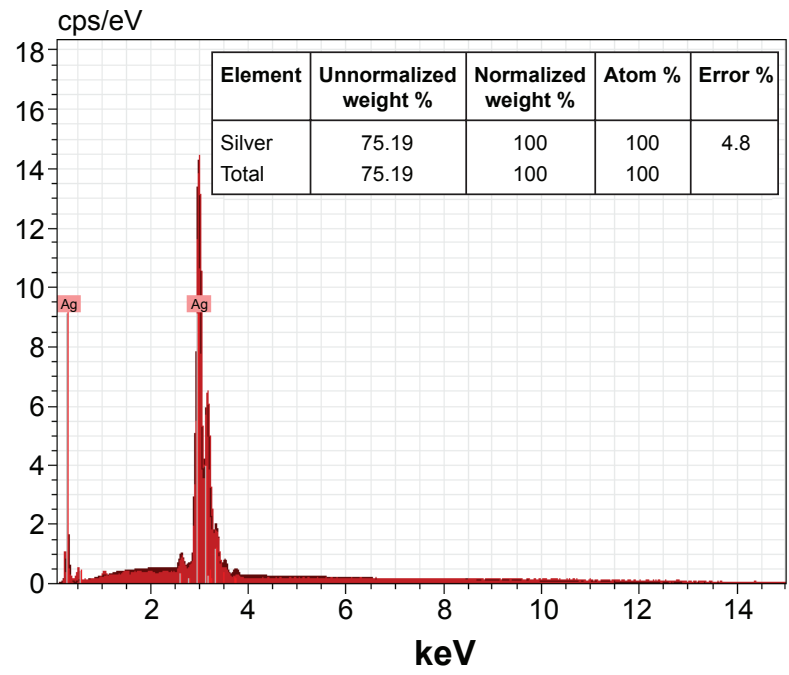

Figure S3 EDS analysis of AgNps.

Abbreviations: AgNps, silver nanoparticles; EDS, energy dispersive spectroscopy.

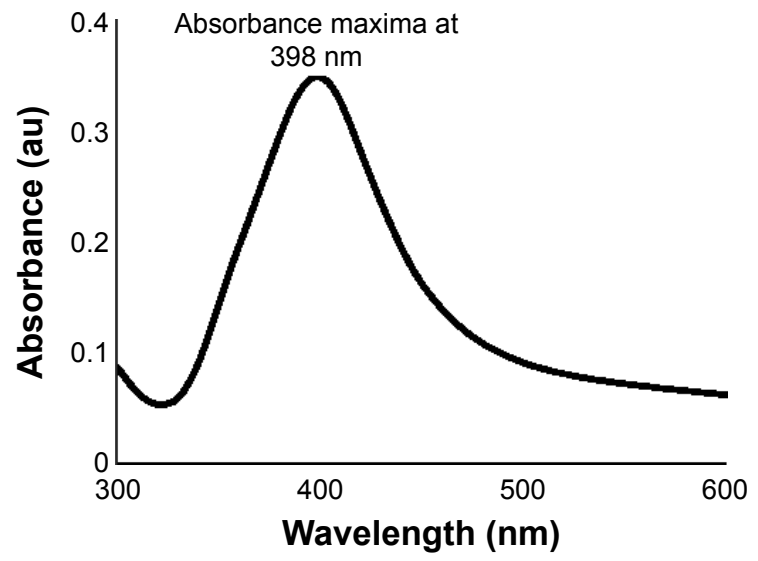

Figure S4 UV-Vis spectra of chemically synthesized AgNps.

Abbreviations: AgNps, Silver nanoparticles; au, arbitrary unit; UV-Vis, ultravioletvisible.

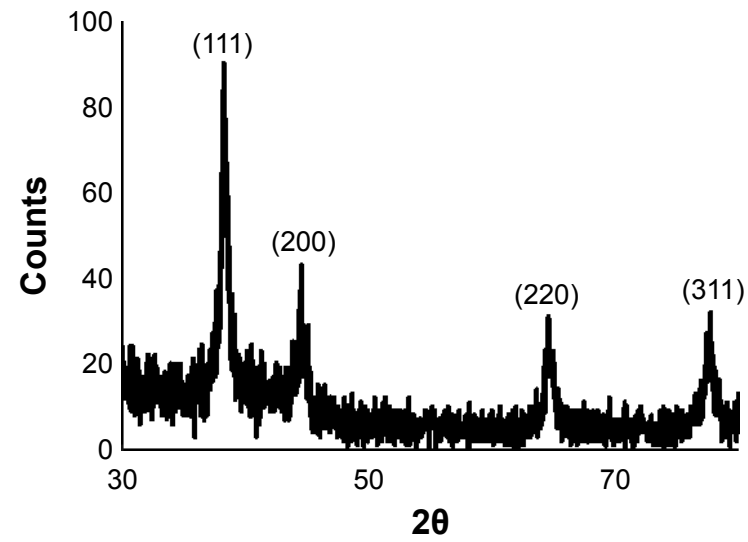

Figure S5 X-ray diffraction pattern of AgNps. Abbreviation: AgNps, silver nanoparticles. 


\section{Publish your work in this journal}

The International Journal of Nanomedicine is an international, peerreviewed journal focusing on the application of nanotechnology in diagnostics, therapeutics, and drug delivery systems throughout the biomedical field. This journal is indexed on PubMed Central, MedLine, CAS, SciSearch $\AA$, Current Contents $\AA /$ Clinical Medicine,

Journal Citation Reports/Science Edition, EMBase, Scopus and the Elsevier Bibliographic databases. The manuscript management system is completely online and includes a very quick and fair peer-review system, which is all easy to use. Visit http://www.dovepress.com/ testimonials.php to read real quotes from published authors.

Submit your manuscript here: http://www.dovepress.com/international-journal-of-nanomedicine-journal 